\title{
The Internet and Differentiation in the Political Public Sphere
}

\author{
Terje Rasmussen
}

Habermas's main question in his keynote address to the media researchers at the ICA conference in Dresden in June $20^{\text {th }} 2006$ was whether deliberation in the public sphere actually does introduce an epistemic dimension to political decision-making, ie. whether the public sphere can bring new insights and solutions to politics today. As known, Habermas has previously given arguments for the potential of the public sphere, but what about the current condition in western democracies? The volume of political communication in the public sphere has expanded dramatically, but it is at the same time dominated by nondeliberative communication. Habermas argues that there is a lack of an egalitarian faceto-face interaction and reciprocity between speakers and addressees in a shared practice of collective decision-making (Habermas 2006, 414). More importantly, the very dynamics of mass communication, Habermas claims, are driven by the power of the self-regulated system of the mass media to select, and shape (dramatise, simplify, polarise) information. Quite interesting, he presents something of a media-centric argument, suggesting that the increasing influence of radio and TV, fosters increasing ignorance, apathy and low-level trust in politics: 'The data I have mentioned suggest that the very mode of mediated communication contributes independently to a diffuse alienation of citizens from politics.' (Habermas 2006, 424) But the strategic use of political power to influence and trigger agendas and issues is according to Habermas also an increasing problem. In other words, in the public sphere of communicative action, strategic action has continued to intervene.

To Habermas, these facts does not refute the validity of the deliberative model of democracy, because the public sphere precisely has the function of 'cleansing' or 'laundering' flows of political communication. From the processing and compartmentalising of the wild and diverse communication (entertainment, shows, news reports, commentaries, etc) in the public sphere, politics struggle to select relevant information (problems, arguments, solutions). As a platform for the pubic sphere, the media sector possesses certain rules, which the players must play according to, in order to be taken seriously and to be efficient. Through deliberation, the pubic sphere is able to raise issues, provide arguments, specify interpretations and propose solutions. In the pubic sphere, demands from social movements and interest groups in the civil society become translated into political issues and arguments and articulate manifest, reflexive public opinions. The model of deliberative communication, Habermas argues, provides a critical standard to which disturbances and constraints in the public sphere can be criticized. For reasons of legitimacy, the political system must keep itself open to the political influence of society. The public sphere thus links to established politics and to the civil society, which must empower people to participate in informed, public discourses. 
What then about the Internet. In his talk, Habermas addressed the Internet only in a footnote, pointing out that interaction on the Internet only has democratic significance in so far as it undermines censorship of authoritarian regimes. In democratic countries however, the Internet serves only to fragment focused audiences 'into a huge number of isolated issue publics'. Habermas claims that: 'Within established national public spheres, the online debates of web users only promote political communication, when news groups crystallize around the focal points of the quality press, for example national newspapers and political magazines.' (Habermas 2006, 422)

One interpretation of this is that Habermas is simply not sufficiently knowledgeable about the myriads of discourses on the Internet about delimited issues as well as questions of national concern to transform his model in accordance with the current media situation. One could get the impression that he considers the mediated dimension of the public sphere as mainly composed by the press, increasingly challenged by radio and TV. But this would certainly be to underestimate Habermas as an observer of contemporary changes. Rather, I believe that his passing comments on the Internet derives from his prime interest in the public sphere seen from the point of view of political democracy and less from the point of view of media research. Habermas is simply more interested in political deliberation than in democratic potentials in media change. Also, he is concerned with the deliberative legitimation of politics in differentiated and complex societies, which requires some kind of public focusing and ordering of issues and solutions. In Habermas' examination, this leads to a focus on the dimensions of the political public sphere that directly influence legitimate, political decision-making by providing thematic focus and consolidation.

The notion of the public sphere is the key. Habermas argues that the public sphere can facilitate deliberative legitimation only if a self-regulating media system gains independence from the social environment, and if anonymous audiences grant feed-back between an informed elite and a responsive civil society. Civil society can be understood as the ensemble of self-organised and coordinated activity in organisations, associations, social movements and interest groups where members freely cooperate on equal grounds to publicly pursue aims of common or universal interest. The communicational dimension of the civil society can be viewed as a dimension of the public sphere.

So how can we advance our thinking about the relationship between deliberative democracy and the Internet? If the research problem is not deliberative legitimation of politics per se, but rather the significance of Internet communication in the public sphere, we need to a) address local and global public spheres in addition to the national, b) address the literary/cultural public sphere in addition to the political, and c) address the communication that has indirect influence on the political system in addition the communication with direct influence. We should ask what normative energies and burdens the Internet brings to the public sphere. How does it structurally transform the public sphere, not least on a European scale?

My argument here is threefold: First, the use of the Internet contributes to the diversity of views and broadening participation, but complicates observation of the political public sphere from the point of view of politics and the state. In this, the Internet seems to reverse the effect of commercial mass media. Second, the public sphere should be seen as consisting of two epistemic dimensions or 'faces', each oriented towards different solutions and problems. Third, an updated understanding of the public sphere would benefit from a network-analytic approach. 


\section{Differentiation of Public Communication}

The press, cable TV and national broadcasting distribute mass communication from relatively few, centralised senders to a large number of unconnected receivers, who receive the communication in more or less similar ways. The mass media thus functions as centralised filters of public communication. Due to the cost of (mainly advertisingfunded) production, content tend to be mainstreamed and directed towards the imagined, implied average receiver/consumer. Content are pre-produced in a limited number of editorial centres and then disseminated widely for mass consumption. The possibilities for feed-back are extremely limited.

These features are often seen as contra-productive and disadvantageous for an active, participatory public sphere. However, they fill a very important function of the public sphere, the function of focus, in terms of both content and form. The standardised, narrowed and centralised agenda of the mass media enables the political system to mirror their own deliberation in the public sphere and become visible for the citizens. The problem with the mass mediated platform is not the mass media structure itself, but that this structure have only been complemented by place-bound, face-to-face interaction. I am not here referring to the concentration on the international media market (which constitutes a democratic problem indeed) but the inherent structure of mass media and mass communication. While it inhibits participation and diversity from below, it allows for an organised harmonisation and convergence of meaning as an interface of the public sphere for the society to observe. The amorphous public can thus be identified and referred to, and mobilised as platform for democratic politics. We should however, remember that the vast numerical majority of mass media in Europe (newspapers, weeklies, magazines, journals, local radio, and tv stations etc.) have modest circulation and audiences, but which makes them more sensitive to the diversity of topics, people and events of interest.

The Internet-based structures of communication, whether we look at e-mail, mailing lists, wikis, blogs, chat groups or network sites like Facebook, clearly represent deviations from the mass media model. In very different ways, they all base their existence on information and communication from their users, including a wide variety of participants, events, views and topics. Not surprisingly, media theory and Internet-research turned rather quickly to Habermas' study of the early European bourgeous public sphere and to theories of deliberation. Theories of deliberation addressed precisely what the Internet seemed to offer: Possibilities for formation of productive enlightening and public opinion on a much broader scale than previously in history. This provided formation of public opinion as a medium between citizen preferences and political institutions. Several studies have demonstrated that digital forums of various sorts have the capacity to create engagement, and critical discussion about important issues of common public interest (Coleman \& Gøtze 2001). Several studies have examined the ability of the Internet to carry public deliberation (for an overview see Dahlberg 2001). The conclusion is that fora on the Internet contribute to the critical public sphere, whether locally, nationally or internationally by reproducing normative conditions for public opinion formation.

However, Habermas is not entirely off the mark in insisting that the Internet play a secondary role vis-à-vis formal politics. In order for a blogger or a group on the Internet to have political impact, their message must in almost all cases be picked up by the mass media. And before we go on to modify the model of the public sphere according to the media development of the last decade or two, we should also keep in mind the naïve 
wave of cyber-democratic enthusiasm that tend to confuse political and technological realities (Benkler 2006). What is technologically possible may not be socially favourable. For instance, even if hypertext makes it technically possible to connect issues, publics, arguments, and facts, research shows that this possibility is often not applied in practice. And although it is perfectly possible to engage in civil debates on discussion forums, such forums often report on problems of uncivil communication in various forms. What seemed to worry Habermas is precisely that communication evades responsible editing mechanisms. Substantial parts of Internet interaction seems to amount to hasty, unfocused and inconsistent chat because of the expansion and democratisation of access to un-edited discussion that the Internet offers.

First, what Habermas calls 'issue publics' overlap with publics with interest in social and political change, which is pursued through other media. Membership in various publics, either with respect to themes or media (magazine readers, human movements activists, bloggers, tv-viewers, etc.) is not mutually exclusive. Second, the diversity of Internet communication (measured as scope of issues and viewpoints, degrees of civility) is larger than in the mass media, thus representing the worst and the best from the point of view of rational discourse. To control the explosive growth of information on the net, socio-technological tools are developed to search, filter and target information on the net (tags, filters, blog-lists, RSS-feeds, search-engines, meta-sites, tracking systems, etc).

Third, with the Internet, the collective, main-stream nature of the hitherto mass mediated public sphere, become more in tune with individualisation of modern society. With interaction rather than reception, subjective preferences and viewpoints are more easily articulated and linked to others, reproducing webs of intersubjectivity. The autonomy and self-realisation typically associated with the modern individual 'fits' better with the public sphere partly reproduced through what I call personal media. Personal media represents the modern individual's personal tool in that they allow not only for social interaction with friends and relatives, but also for critical judgement vis-à-vis others in weak-tie associations that are linked together with new and old media.

As personal media allow more people to produce texts and take part in communication, the Internet offer new forms of access to public authorities, new channels of coordination and influence for social movements, and a multitude of more or less stable settings for chat and discussions. On all accounts, digital media provide, quite different circumstances for communication than the mass media. The most central ones can be listed as follows:

1. Social Movement activity (web, blogs, email, wikis)

2. Discussion and chats among citizens (blogs, chatrooms, e-maling lists)

3. Citizen access to MPs and public authorities (web, e-mail, blogs)

4. Online 'participatory' journalism (web, email, sms, mms, blogs)

5. Connections and weak tie networks (network sites like Facebook, Myspace etc.)

6. User-generated content in broadcasting (tv, radio, web, sms, blogs)

In contrast to the public sphere once entirely dominated by public encounters and the mass media, the Internet and personal media propels a more differentiated public sphere, both in terms of topics, styles, as well as with respect to the number and variety of participants. The current public sphere are more niche-oriented, both because of a more diverse media-scape, and because of a more ethnically and culturally pluralistic 
society in general. First, the diversity of topics is broader than in the mass media; It has been argued that the nature of topics in the more recent representational dimension of the public sphere are more particular, private and local than the mass media, in spite of the global reach of the net (Becker \& Wehner 2001, 74). However, it is also the case that global or international issues are constantly discussed, such as the conflicts in Iraq, if in individual and local ways. Second, the span of styles and genres (informality, impulsivity, rhetoric styles, politeness, civility etc) far exceeds the mass media. Third, the number and diversity of voices is considerable compared to the mass mediated public sphere. (children, youth, people holding extreme viewpoints, etc.). Individuals may change between the roles of general relatively passive citizen and more active and specialised communicator.

The differentiation of topics, styles and participants is truly an astonishing phenomenon, which transforms the public sphere and how we view it in relation to democracy and culture. In all three differentiation trends, the driving force is the personalisation of media on the Internet, enabling the individual to voice opinion directly to public power, to participate in campaigns, and social movements, and to exchange opinions on online forums in her own ways and language, drawing upon personal experiences, knowledge, engagements, values and judgements. Because the threshold for speaking up on the Internet decreases, more people do, and increasing participation lower the threshold even further. And yet because the threshold is still much higher than simply watching the television news, more involvement and interest accompany Internet participation. One tends to appear more as one interested in particular themes and interests, than simply being a citizen among millions (Becker \& Wehner 2001, 74). Whereas the mass media produce homogeneity, the multitude of Internet fora seems to produce a heterogeneity that has, I might add, difficulties in controlling itself communicatively.

Consequently, the Internet takes actively part in the current dramatic differentiation of the public sphere, in terms of topics debated, styles applied and persons involved. The diversity of communication on the net, is in part caused by anonymity and quasiorality (and therefore more extreme viewpoints and considerably uncivil characteristics, unconventional ways of argumentation), diversity of communication forms (from chat forums to blogs and homepages with comment functions), and diversity of inter-textual connections between forums (hyperlinks, RSS feeds, network sites). In its reciprocity, heterogeneity and resistance to censorship it stands in a complementary position to the mass media. Particularly the national and international mass media enable broad attention around some prioritised public topics 'of national interest', and so serves as a resonance for national and international politics. The Internet and personal gatherings underline the individualisation and segmentation of modern societies, in that attention and engagements are spread among a wider range of topics, which make a political focus difficult to trace.

As a modern response to a dynamic democracy, the digital dimension of the public sphere offers less guidance for politics, but more possibilities for expression. Compared to the journalism of mass media, on-line journalism tends to be more compartmentalised and based upon self-selection and personalisation. The criteria of selection are to be composed by the individual. Rather than offering carefully edited information, it offers a differentiated space for interaction and user-composed information, that tend to be rather specialised, and also closer to personal opinion, rumour and not confirmed information. Whereas the mass media works toward conformity and common denominators, the Internet is more oriented towards particular interests. It is located 'between' 
the mass media public, and face-to-face interaction, as in public meetings, rallys, etc. (Becker \& Wehner 2001, 75).

Studies also show negative side-effects of the new forums: polarisation of debates, isolation of issue-based groups, unequal participation, lack of responsiveness and civility in debates, etc. For these and other reasons, the value of digital forums in a public sphere context is questioned. A main problem addresses their numerous, local, segmented character, which makes it difficult to see how their normative communication may integrate into larger sentiments of public opinion (Kraut et. al 1998). What seems to be missing in many forums on the Internet is a culture for civil, public communication, or simply a public culture. Due to the lack of personal experience in an open space and the absence of editing functions, communication often has a private style, in spite of its open and widely accessible nature. In spite of being public, it draws on genres for private communication. This has two problematic consequences: 1) The discussion has problems with the complexity of the issues discussed, and 2), the discussion has problems reaching a self-referential, self-critical level where the normative aims of the discussion are subject for discussion. In other words, the responsibility that normally embody public communication (publicity), is to a lesser extent taken into consideration in the nature of the interaction.

Still, the vast majority of these forums fulfills some basic requirements of a public sphere: they are (just like the mass media and locale meetings), committed to improve social conditions one way or another, and also to free speech and dialogue. They are also committed to make themselves understood and to understand others in an open space of an assumed indefinite audience, if not for other reason than to make rhetorical shortcuts or reach compromises. Some sort of communicative or cooperative action with embedded validity-claims, may seem to be in action.

At first glance, there are few and weak functional equivalents to editing and regulatory agencies, like editors, journalists and judges (Bohman 2004,143). However, there are in fact plenty of intermediaries on the Internet, as in online journalism and moderators, filters and other software systems, the norms of social movements and organisations, which all serve to normalise communication in one way or another. In spite of its 'anarchic' nature, much of the communication on the net is embedded in larger normative frameworks that tend to discipline interaction. Second and more importantly, we should not assume that the Internet is isolated from the mass media and face-to-face meetings as a platform for a public sphere. The intertextuality of meaning and communication in and out of forums in the public sphere are innumerable. The lack of intermediaries on the Internet is less of a problem than it may seem, precisely because it is so integrated with face-to-face, and mass mediated interaction.

\section{Dimensions of the Public Sphere}

In taking the differentiation of the public sphere seriously, I distinguish between two dimensions of the public sphere, related to topics, style and participants, and also with reference to different functional emphasis (Rasmussen 2007). The representational dimension refers to the heterogeneity of topics, styles and groups that take part, and which reflects culture and everyday life, only seen before in everyday conversations and more or less peripheral social settings (clubs, parties, unions, therapy groups, etc.) With the expansion of this dimension through digital media, the public sphere is now becoming increasingly differentiated and diversified with regard to people, issues and attitudes. 
In a numerical sense it is becoming more democratic and inclusive. This dimension is oriented towards culture, sports, science and everyday life, as well as politics. In the representational dimension, extensive differentiation of themes and styles are not balanced by generalisation.

The presentational dimension refers to the deliberation over common issues by central figures acting as voices of the people. It presents a public agenda and an expression of public opinion to politics as a resonance for rational decision-making. Its procedural ideal is rational discourse of argumentation and reasoning. It is primarily oriented towards homogeneity, focus and the political system (but never fully entering it). This dimension is at the centre for Habermas' concern. Historically, the mass media has been a vital cause and effect of this differentiation of communication. In this they represent increasing complexity and contingency. However, equally important is that the mass media generalise communication by allowing variation within certain standards or common denominators that transcends singular contexts. By applying recognisable genres and referring to a limited number of issues, communication and understanding becomes 'less improbable' to use Luhmann's phrase, by stabilising expectations. In this way they reduce contingency, and in relation to political democracy they enable mutual observations between the public sphere and politics. This function of generalisation is predominantly effectuated in the presentational face of the public sphere.

How the Internet is involved with these two dimensions is an empirical question, and empirical research more than indicate that the Internet serves the representational dimension more than the presentational. Increasingly, the political system examines the possibilities of the Internet as a forum for political will formation and deliberation, but such attempts are risky. Due to the proliferation of personal media among individuals, they are used mostly as channels for citizen activity in the civil sphere and everyday life. The heterogeneity of Internet communication stands in a dynamic relationship to the homogeneity of the main stream mass media, through a wide range of mechanisms of selecting, filtering, styling, formalisation, restructuring etc. If such integration occurs, reciprocity emerges between the presentational and representational dimensions. More precisely, in such a dialectic process, the mass media present mainstream issues (and mainstream positions to them) to the broader audience, and to central powers of politics, but also economics, courts, sports, entertainment, social movements, etc. On the other hand, substantial information and communication on the Internet are produced and consumed by culturally, demographically and politically segments of the public.

A dynamic relationship between its presentational and representational faces implies that the public sphere serves its purpose as a political and cultural institution. Both dimensions serves basic functions to a democracy which depends on, and appreciates both efficiency and diversity, both a strong public opinion, which motivate politics on main concerns with the help of journalistic and entertainment techniques, and pluralistic and direct dialog among its citizens. Diversity is increasingly important, not least because the mass media in most countries tend to be subject to concentration in large-scale media cartels. And conversely, a focused and mainstreamed public sphere compensate for the complexity, extremity and intransparency of partial, issue-oriented, public contexts.

It may sound like a contradiction in terms to say that the public sphere both increases and reduces complexity of social interaction, but indeed this is the paradoxical effect of handling differentiation. As topics move interferensically and transcontextually between the presentational and representational dimensions of the public sphere, increasing complexity from new topics, styles and participants are kept under control through its 
ability to concentrate the wide audience among some focused themes. And vice versa, the focused and generalised agenda of the public sphere, continuously receives fresh meaning from the open-ended, partly non-institutionalised diversity of Internet media and small mass media.

The criteria of quality of such a new public sphere derive, therefore, not simply from the relationship between the mass media and politics (which is a main focus in contemporary political science and media research). Nor is it only a question of (the lack of) diversity in the mass media due to concentration and competition (another heavily researched problem within the area of political economy). Empirical research on the quality of the public sphere needs to take the Internet into account as a functional complement to big mass media and face-to-face interactions, and the effects of this. A vibrant and democratic public sphere depends on its internal composition and dynamics, particularly whether the two dimensions are integrated with one another through networks of media, themes, opinions and knowledge crossing in various ways and shapes between its 'compartments' and realms.

In order to understand the interrelationships between the two faces of the public sphere as well as their connection to political democracy, let me briefly recall Habermas' two forms of discourse - the moral and ethical-existential (Habermas 1996). The aim of moral discourse is to find an impartial platform for sorting out collective courses of action on collective matters. The question of moral discourse is what we (in this society) should do. On the other hand, the aim of ethical-existential discourse is not concerned about how we should solve common problems through rational procedures, but rather how the individual should organise her life according to values and norms. The question is: What is the good life for me - who do I (or a cultural/ethnical 'we') want to be. This duality of discourse has been criticised for being too sharp, and for devaluing cultural values involved in moral discourse. In reality, it is argued, my private world of values and norms and the public world of problem-solving are to a large extent intertwined, we always draw on the one world to deal with the other. Furthermore, Habermas is criticized for seeing the ethical discourse as secondary compared to the moral discourse, and therefore tends to reduce the value of feminine, ethnic, and other discourses that go on 'in a different voice', to draw on Carol Gilligan's title (Gilligan 1982). Habermas' impartial discourse, Gilligan argues, is male, not universal.

If perhaps rigid, I think the distinction nevertheless is useful in order to understand the challenges that a modern public sphere is confronted with. The public sphere possesses two faces also in democratic respects, in Habermas' terms a moral and an ethicalexistential. The line between the two faces are surely impossible to draw, but should be assumed analytically in order to see functions of the public sphere. We should see the public sphere as a medium between individual voices of a public on the one hand, and the political apparatus on the other. The public sphere transforms and transfers individual opinion into public opinion for the political system to take into account. A voluntas, as Habermas once formulated it, becomes transformed into a ratio, a consensus about what is practically necessary in the interest of all. To carry out this task, the public sphere must front both the people and politics, by addressing problems and issues as both moral and ethical-existential, and juggling issues between the two. Whereas the moral deliberative discourse are directed to politics and common problems and alternative solutions, the ethical-existential discourse constitute its social and cultural foundation, its reference background and test-bed, its source for ideas and fresh thinking, with fewer conformity and constraints that press for consensus, more controversy, drama, agitation and passion. 
The ethical-existential discourse is more characterised by religious and other kinds of values and convictions that rarely becomes modified through discourse.

\section{Conclusion}

With the pluralisation and individualisation of society, differentiation became a problem in the public sphere. The active use of personal media is one factor that led to difference and what Pellizoni (2003) calls (with Kuhn) incommensurability. This difference is a major challenge for theories of deliberation. In Rawls and Habermas, rational deliberation must find some common ground, based on moral arguments of justice, leading to consensus or binding compromises. However, a differentiated public debate is not to be avoided, and I have argued that the increasing use of personal, digital media accelerate the differentiation trend. While the Internet is often seen to be an obvious argument in favour of deliberative models of democracy, it also poses some serious challenges, due to increasing fragmentation and complexity. When we examine the basic normative assumptions of the idea of a public sphere, it becomes clear that the Internet and personal media bring about changes in conjunction with other transformations in society, which pose both new problems and solutions to democracy.

While digital media brings increasing participation (and inequalities), fresh viewpoints and new solutions, it is harder to see how they enable consolidation and oversight. I do not argue that personal media are antithetical to the idea of a public sphere, but that they contribute much more to diversity than to convergence. Legitimacy and effectiveness of the public sphere and the democracy as a whole is dependent on not only diversity, but also coherence. How is the modern public sphere able to tackle its own indeterminacy, fragmentation and complexity? In Habermas' model, procedural debates ensure that consensus does not have to rely on common ethical values to be actualised. The model assumes pluralism, not ethical conformity. This, however, requires that the discursive threads in various media and forums actually become connected. This is not necessarily the case with the Internet. Both sociology and media studies have focused on individualisation and the dependence of the individual on expert-systems. The consequences for the public sphere have been underestimated.

The possible solution lies on several levels, inside and outside the media, and in both the personal media and particularly the mass media. The mass media front this process vis-à-vis the national political systems. This will be status for many years to come. The reason for this is not simply technological conservatism, but is related to the structural features of the media as suitable carriers for a public sphere with democratic and political ambitions. The mass media are characterised by a rupture between senders and receivers, with limited possibilities for feed-back. This essential feature allows for public opinion to disseminate and circulate among elites and intellectuals, to be dealt with by languages of expertise, to transform into relatively consensual bodies of ideas, and to be easily scanned by the political system. Voices of opinion have the possibility to observe, to understand and to learn from one another.

Whereas big media like national public service broadcasting and the larger quality news-papers can be regarded as a main arenas for a public sphere, political deliberation is increasingly inter-medial in that discourse circulates through very different kinds of media, from amateur blogs to Financial Times. The question of media's influence on public discourse is therefore a more complex question than in the previous mass mediated (and technically unmediated public sphere. However, whereas the post-modern approach 
ignores the legitimacy question entirely, I think it is essential to distinguish between media of diversity and media of focus. Whereas the first group of media enhances pluralism of topics for society, the latter represents what potentially become the agenda for formal politics. Whereas the Internet still tends to belong to the first group, elite quality newspapers and some broadcasting programs tend to represent the latter group. Thus in spite of widespread inter-mediality of the polyphony of public communication, the specifics of various media types tend to coincide with the two dimensions of the political public sphere.

\section{References}

Bakhtin, M.M (1981) The Dialogic Imagination. Four Essays by M.M. Bakhtin. (M. Holquist ed.). Austin: The University of Texas Press.

Becker, Barbara and Wehner, Josef (2001) 'Electronic Networks and Civil Society: Reflections on Structural Changes in the Public Sphere', in Ess, Charles (ed.) Culture, Technology, Communication. Towards an Intercultural Global Village. Albany: State University of New York Press.

Bohman James \& Rehg W. (eds.) (1997) Deliberative Democracy. Cambridge, MA: The MIT Press

Bohman, James (2004) 'Expanding Dialogue: The Internet, The Public Sphere and Prospects for Transnational Democracy', in Crossley, Eric and John Michael Roberts (eds.) After Habermas. New Perspectives on the Public Sphere. London: Blackwell.

Brandenburg, Heinz (2003) 'Pathologies of the Virtual Public Sphere', The European Consortium for Political Research (ECPR) Edinburg.

Van der Brink, Bert and David Owen (2007) Recognition and Power. Axel Honneth and the Tradition of Critical Social Theory. Cambridge: Cambridge University Press

Calhoun, Craig (ed.) Habermas and the Public Sphere. Cambridge, Mass.: The MIT Press.

Crossley, Nick and John Michael Roberts (2004) After Habermas. New Perspectives on the Public Sphere. Oxford: Blackwell/The Sociological Review.

Cummings, J.N. \& Kraut, R. (2002) Domesticating Computers and the Internet. The Information Society, 18( 3) 221-231.

Coleman, Stephen \& John Gøtze (2001) Bowling Together: Online Public Engagement in Policy Deliberation. London: Hansard Society.

Dahlberg, Lincoln (2001) 'Computer-Mediated Communication and The Public Sphere: A Critical Analysis', Journal of Computer-mediated Communication, 7(1).

DiMaggio, P. et. al. (2001) 'Social Implications of the Internet', Annual Review of Sociology, vol. 27( 1) 307336.

Eriksen, Erik Oddvar (2005) 'An Emerging European Public Sphere', European Journal of Social Theory. 8(3) 341-363.

Gershuny, Jonathan (2003) 'Web Use and Net Nerds: A Neofunctionalist Analysis of the Impact of Information Technology at Home', Social Forces, 82(1) 141-168.

Gimmler, Antje (2001) 'Deliberative Democracy, The Public Sphere and the Internet', Philosophy and Social Criticism 27(4) 21-39.

Habermas, Jürgen (1993) 'Further Reflections on the Public Sphere', in Craig Calhoun (ed.) Habermas and the Public Sphere. Cambridge, Mass.: The MIT Press.

Habermas, Jürgen (1996) Between Facts and Norms. Contributions to a Discourse Theory of Law and Democracy. Cambridge, Mass.: The MIT Press.

Habermas, J. (2005) 'Concluding Comments on Empirical Approaches to Deliberative Politics', Acta Politica 40, 384-392.

Habermas, Jürgen (2006) 'Political Communication in Media Society: Does Democracy Still Enjoy an Epistemic Dimension? The Impact of Normative Theory on Empirical Research', Communication Theory 16(4) 411-426.

Johnson, Pauline (2001) 'Habermas's Search for the Public Sphere', European Journal of Social Theory, 4.

Keane, John (1994) 'Structural Transformations of the Public Sphere', in Bruun-Andersen (ed.) Media and Democracy. University of Oslo: Dept. of Media and Communication.

Lievrouw, L.A. (2001) New Media and the Pluralisation of Life-worlds. New Media and Society 3(1) 7-28.

Lincoln Dahlberg, www.ascusc.org/jcmc/vol7/issue1/dahlberg.html

Meehan, Johanna (1995) Feminists Read Habermas. London: Routledge. 
Pellizzoni, Luigi (2003) 'Knowledge, Uncertainty and the Transformation of the Public Sphere', European Journal of Social Theory, 6(3) 327-355.

Perzynski, Adam (1999) Habermas and the Internet, http://socwww.cwru.edu

Peters, Bernard (1997) 'On Public Deliberation and Public Culture. Reflections on the Public Sphere', InIISArbeitspapier no. 7/97. University of Bremen.

Peters, Bernhard et. al. (2005) 'National and Trans-national Public Spheres: The Case of the EU', European Review, 13(1) 139-160.

Poster, Mark (1990) The Mode of Information. Poststructuralism and Social Context. Cambridge: Polity Press Poster, Mark (1995) The Second Media Age. Cambridge: Polity Press

Rasmussen, Terje (2007) Two Faces of the Public Sphere. The Significance of Internet Communication in Public Deliberation. Paper presented at the conference Changing Politics through Digital Networks. October, University of Florence, Italy.

Rawls, John (1993) Political Liberalism. NY: Columbia University Press.

Ruth, Arne (2007) The Press and Europe's Public Sphere, wwwsignandsight.com 09/05/2007

Schlesinger, Philip (1999) 'Changing Spaces of Political Communication. The Case of the European Union', Political Communication (16) 263-279

Shah D. V. et. al (2001) 'Connecting and Disconnecting with Civic Life: Patterns of Internet Use and the Production of Social Capital', Political Communication 18(2) 141-162.

Slaatta, Tore (2006) 'Europeanisation and the News Media: Issues and Research Imperatives', Javnost/The Public, 13(206)1: 5-21

Uslaner, E.M. (2004) 'Trust, Civic Engagement and the Internet', Political Communication, 21(2) 223-242.

Villa, Dana R. (1992) 'Postmodernism and the Public Sphere', American Political Science Review 86(3) 71222. 